Letter to the Editor

\title{
Lacrimal system obstruction after cataract surgery
}

Elizabeth M McElnea FRCOphth, Alice E Dutton MBBS(Hons), Khami Satchi FRANZCO and Alan A McNab FRANZCO

Orbit, Plastic and Lacrimal Clinic, Royal Victorian Eye and Ear Hospital, East Melbourne, Victoria. 2. Department of Ophthalmology, University of Melbourne and Centre for Eye Research Australia, Melbourne, Victoria.

Correspondence: Dr Elizabeth McElnea; Address: Royal Victorian Eye and Ear Hospital, 32 Gisborne St, East Melbourne VIC 3002, Australia

Email: mcelneaelizabeth@gmail.com

Received 3 April 2019; accepted 14 April 2019

Funding sources / Financial disclosure: None

Conflict of interest: None

This is the author manuscript accepted for publication and has undergone full peer review but has not been through the copyediting, typesetting, pagination and proofreading process, which may lead to differences between this version and the Version of Record. Please cite this article as doi: 10.1111/ceo.13521

This article is protected by copyright. All rights reserved. 
Epiphora due to postoperative punctal and/or canalicular stenosis or obstruction may follow uncomplicated phacoemulsification surgery.

The records of all patients from the practice of the authors KS and AM complaining of epiphora following cataract surgery and found to have lacrimal system obstruction were reviewed. 18 patients were identified. 14 (77.7\%) were female. Two were affected bilaterally. The right and left sides were affected equally in the remaining cases. This provided 20 lacrimal systems for analysis. The mean age was 71 years (range 35 to 83 years). The mean time from cataract surgery to review because of symptomatic epiphora was 4.5 months.

Five patients were using topical ocular medications prior to their surgery. One such patient discontinued their anti-glaucoma medication following phacoemulsification. Two continued to use timolol maleate, another Refresh ${ }^{\circledR}$ tear drops and the fourth Genteal $\circledast$ eye drops.

Both the upper and lower punctum and/or canaliculus were involved in 16 cases, and either the upper or lower punctum and/or canaliculus were involved in the remaining three cases. The punctum alone was affected in 16 cases, the canaliculus alone in 16 cases, and both the punctum and canaliculus were affected in three cases. When affected, the punctum was stenosed in three, and completely occluded in 16 cases. Canalicular involvement occurred a mean distance of $5.7 \mathrm{~mm}$ from the punctum (range $2-10 \mathrm{~mm}$ ). One case of nasolacrimal duct obstruction was identified. Mild sub-conjunctival scarring was noted in four patients. In seven cases no treatment was undertaken. Three-snip punctoplasty was performed without symptomatic improvement in two cases. One of these patients proceeded to have dacryocystorhinostomy (DCR) with silicone tube intubation with symptomatic improvement.

DCR with silicone tube intubation was performed in a total of seven cases. Four cases symptomatically improved, but the remaining three cases obtained no benefit and subsequently had Lester Jones canalicular bypass tubes (LTT) inserted. Because 
of difficulties with tube position, retention and/or ocular discomfort, two of these were eventually removed, whilst the third patient benefitted with clinical improvement.

DCR with primary LT insertion was undertaken in five cases, with symptomatic improvement in four of these. Due to patient discomfort, the final case required removal of the LJT.

While a direct causal relationship between cataract surgery and epiphora cannot be confirmed, patient statements regarding onset of symptoms following their cataract procedures, the temporal relationship to their surgery and the discrete sites of lacrimal system obstruction described for each case herein establishes, at least, a strong association between the two, and makes other aetiologies unlikely. Lacrimal punctal and/or canalicular obstruction has already been shown to occur after relatively short-term exposures to topical medication, ${ }^{1}$ as well as part of a more widespread cicatricial reaction in patients on longer-term medication. ${ }^{2}$ In some cases, punctal and canalicular obstruction may be the initial presenting feature of cicatrising conjunctival processes. ${ }^{3}$ It is possible that any topical medication may lead to punctal or canalicular obstruction, but some present a higher risk of this. ${ }^{2}$ If a link between topical drop use following cataract surgery and lacrimal system obstruction is genuine, it must be the result of an idiosyncratic reaction. These drops are used for relatively short time periods after cataract surgery but very widely and often for much longer periods in other settings, yet the incidence of these types of lacrimal system obstruction remains very low.

It is possible that the preservatives in these drops are responsible for the reactions seen. Prednisolone acetate, dexamethasone sodium phosphate and tobramycin, all topical medications used frequently after cataract surgery, use benzalkonium chloride as the preservative. Chloromycetin has phenylmercuric acid as a preservative but is not commonly used alone in patients following cataract surgery. 
Furthermore, in some individuals, lacrimal system obstruction may result from the combination of topical treatments used after their surgery, whether these are simply instilled in temporal proximity to one another, or as a combined preparation such as Prednefrin Forte ${ }^{\circledR}$ which contains both prednisolone acetate and phenylephrine. That it occurs in the first place makes the condition worth examining further. To determine the incidence of epiphora after cataract surgery, prospective, randomised studies which consider several potential pathogenetic options should be performed. Ophthalmologists should remain alert to this possibility to detect those medications associated with the highest risk of lacrimal system obstruction following cataract surgery. Avoidance of the same topical medications after fellow-eye surgery may prevent the same event also occurring in that eye.

\section{REFERENCES}

1. McNab AA. Lacrimal canalicular obstruction associated with topical ocular medication. Aust N Z J Ophthalmol 1998; 26: 219-23.

2. Butt Z, Kaufman D, McNab A, McKelvie P. Drug-induced ocular cicatricial pemphigoid: a series of clinico-pathological reports. Eye 1998; 12: 285-90.

3. Satchi K, McNab AA. Conjunctival cicatrizing disease presenting with lacrimal obstruction. Orbit 2016; 35: 321-23. 


\section{University Library}

\section{- M M I N E R VA A gateway to Melbourne's research publications}

Minerva Access is the Institutional Repository of The University of Melbourne

Author/s:

McEInea, EM;Dutton, AE;Satchi, K;McNab, AA

Title:

Lacrimal system obstruction after cataract surgery

Date:

2019-09-01

Citation:

McElnea, E. M., Dutton, A. E., Satchi, K. \& McNab, A. A. (2019). Lacrimal system obstruction after cataract surgery. CLINICAL AND EXPERIMENTAL OPHTHALMOLOGY, 47 (7), pp.948-949. https://doi.org/10.1111/ceo.13521.

Persistent Link:

http://hdl.handle.net/11343/285859 